\title{
Chronic eosinophilic pneumonia complicating long-standing rheumatoid arthritis
}

\author{
C. R. PAYNe \\ M.R.C.P.
}

\author{
S. J. Connellan \\ M.R.C.P.
}

Department of Thoracic Medicine, Papworth Hospital, Cambridge

\begin{abstract}
Summary
A 54-year-old patient with long-standing rheumatoid arthritis developed chronic eosinophilic pneumonia in association with a relapse of his arthritic condition. There was a rapid and complete response to oral steroid therapy.
\end{abstract}

\section{Introduction}

In 1969 Carrington et al. reported a group of patients with a distinctive variant of pulmonary eosinophilia characterized by a chronic illness with fever, nights sweats, weight loss and severe dyspnoea. Two-thirds of their patients developed asthma with the onset of illness and in these a peripheral blood eosinophilia was noted. In all cases the chest radiograph showed characteristic dense, pneumonic infiltrates arranged in a peripheral pattern compared to a 'photographic negative' of the shadow seen in pulmonary oedema. A lung biopsy in each case showed pneumonic consolidation in which the majority of cells were eosinophils. Corticosteroid therapy produced complete clinical recovery with resolution of the abnormal radiographic appearances within a few days. This syndrome was termed chronic eosinophilic pneumonia. A patient with long-standing rheumatoid arthritis is described who developed chronic eosinophilic pneumonia. To the authors' knowledge this has not been reported before.

\section{Case history}

The patient, an Indian Sikh, came to England in 1947. In 1951 a tuberculous gland was removed from his neck. In 1963 he developed seropositive rheumatoid arthritis which improved spontaneously after 12 months, leaving him with considerable deformity in both hands. Serological tests for rheumatoid arthritis subsequently became negative. Six months before admission he developed increasing pain and morning stiffness in both hands and stiffness in both shoulders. He was again found to be seropositive and was treated with indomethacin. After 4 months he noted progressive tiredness and malaise and on referral complained of fever, night sweats, generalized myalgia, anorexia, dry cough, marked exertional dyspnoea, and loss of $3.2 \mathrm{~kg}$ in weight during the previous 3 weeks. There was no history of asthma and in the last 6 months he had taken no drug other than indomethacin.

On examination he was apyrexial and slightly dyspnoeic at rest. Fine crackles were heard over both lung fields and both hands showed marked ulnar deviation and subluxation.

Chest radiography showed numerous peripheral infiltrates in both lungs (Fig. 1). White blood count was $10.3 \times 10^{9} / 1$, eosinophils $9 \%$. Absolute eosinophil count was $0.93 / 1$ and ESR $120 \mathrm{~mm}$ in one hour. RA latex test for rheumatoid factor was positive, antinuclear factor negative. Aspergillus skin-prick test was negative and Aspergillus precipitins were not detected. Serological tests for Filaria and Toxocara were negative and stool examination on several occasions showed no cysts or ovae. There was a sputum eosinophilia but no other sputum abnormality. Pulmonary function testing revealed a moderate restrictive defect, $\mathrm{FEV}_{1} 2 \cdot 15$ litres and FVC $2 \cdot 85$ litres (predicted levels 3.7 and 4.8 litres respectively). Carbon monoxide transfer factor was reduced at $18 \mathrm{ml} \mathrm{CO} / \mathrm{mmHg} / \mathrm{min}$ (predicted $30.4 \mathrm{ml} \mathrm{CO} /$ $\mathrm{mmHg} / \mathrm{min}$ ). Heaf test was positive Grade 3 .

A diagnosis of chronic eosinophilic pneumonia was made on the history and chest radiograph appearances and he was started on oral prednisolone $30 \mathrm{mg}$ daily with rapid symptomatic improvement. After 10 days his chest radiograph was normal. His steroid dosage has been progressively reduced and pulmonary function has since returned to normal.

\section{Discussion}

The illness in this patient is consistent with a diagnosis of chronic eosinophilic pneumonia as described by Carrington et al. (1969) who felt that the clinical and radiographic manifestations of this disorder and the rapid response to corticosteroid therapy are sufficiently distinctive to permit diagnosis without biopsy. None of their patients had rheumatoid arthritis and arthritis has not been noted in subsequent reports (Morrissey et al., 1975). Moreover rheumatoid arthritis is not a recognized cause of pulmonary eosinophilia (Crofton et al., 1952). 


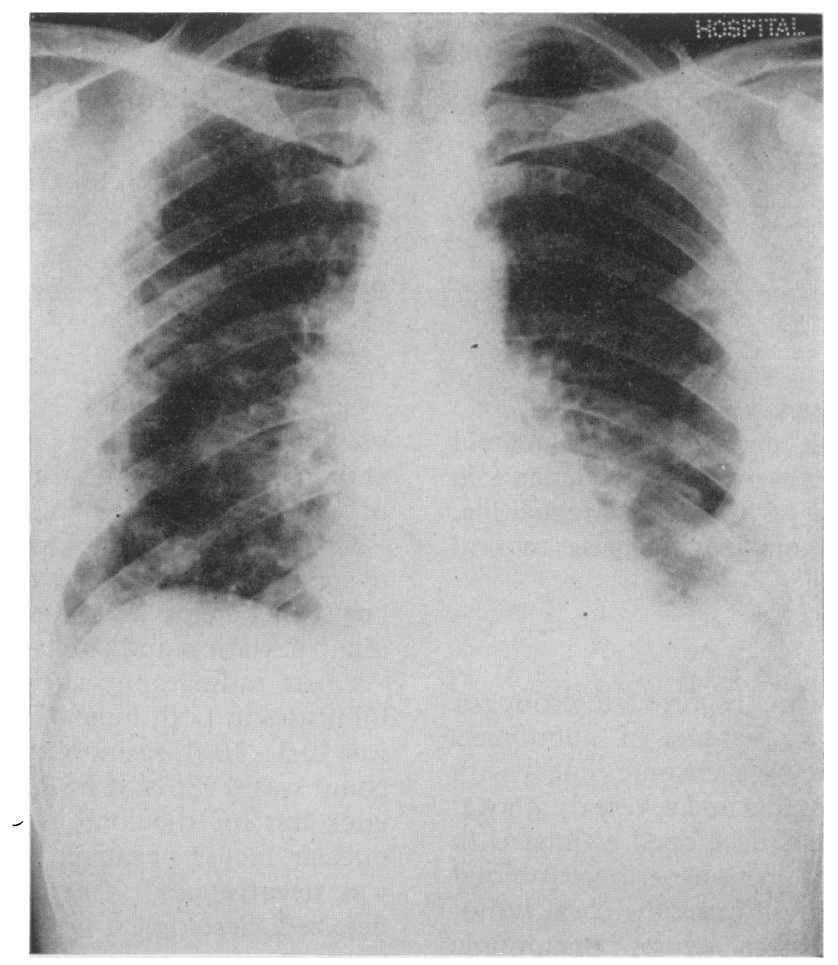

Fig. 1. Chest radiograph on admission showing bilateral peripheral shadows.

Pneumonic shadowing is known to occur infrequently in patients with rheumatoid arthritis but eosinophilia in these cases is not described and radiographs have shown lobar, often basal, changes rather than the multiple peripheral opacities typical of chronic eosinophilic pneumonia (Beck and Hoff brand, 1966).

Panush, Alejandro and Schur (1971) reported marked blood eosinophilia in 5 patients with severe deforming rheumatoid arthritis and noted a high prevalence of vasculitis, pleurisy and subcutaneous nodules. None of these patients had pneumonic changes on chest radiography.

In this patient the exacerbation of rheumatoid arthritis was directly related to the development of chronic eosinophilic pneumonia, implying a common underlying pathogenetic link the precise nature of which remains unclear. It therefore raises the possibility that rheumatoid arthritis is another rare cause of pulmonary eosinophilia.

\section{Acknowledgment}

The authors wish to thank Dr E. M. Cheffins for permission to report this case.

\section{References}

Beck, E.R. \& HoffBrand, B.I. (1966) Acute lung changes in rheumatoid arthritis. Annals of Rheumatic Diseases, 25, 459.

Carrington, C.B., Addington, W.W., Goff, A.M., 윽 Madoff, I.M., Marks, A., Schwaber, J.R. \& Gaensler, E.A. (1969) Chronic eosinophilic pneumonia. New England Journal of Medicine, $280,788$.

Crofton, J.W., Livingstone, J.L., Oswald, N.C. \& $\frac{7}{0}$ Roberts, A.T.M. (1952) Pulmonary eosinophilia. Thorax, $7,1$.

Morrissey, W.L., Gaensler, E.A., Carrington, C.B. \& Turner, H.G. (1975) Chronic eosinophilic pneumonia. N Respiration, 32, 453.

Panush, R.S., Alejandro, E.F. \& Schur, P.H. (1971) Rheumatoid arthritis associated with eosinophilia. Annals of Internal Medicine, 75, 199. 